\title{
Comparison of push-out bond strength of bioceramic sealer with bioceramic coated and non-bioceramic coated Gutta-percha: an in vitro study
}

\author{
Srikanth Garikapati1,", Kalyan Satish R², Girija S Sajjan², Madhu Varma K², Vishal Babu Kolla1, \\ Rajashekar $\mathrm{Ch}^{1}$ \\ ${ }^{1}$ Postgraduate Student, ${ }^{2}$ Professor, Department of Conservative Dentistry and Endodontics, Vishnu \\ Dental College, Bhimavaram -534202, Andhra Pradesh, India.
}

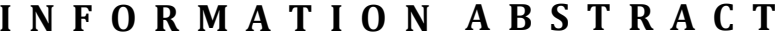

\section{Article History}

Received 20th July 2020

Accepted 19 August 2020

Available online

27 August 2020

\section{K E Y W O R D S}

AH Plus sealer

Endosequence BC sealer

Bioceramic coated GP

Push-out test

Bond strength
Background: The goal of the endodontic treatment is to achieve a fluid-tight impervious seal to prevent the ingress of bacteria and the occurrence of any pathology in future. The endodontic sealer plays a crucial role in obtaining the hermetic seal by filling all the spaces and by binding to the root dentin and to the core obturating material, which is usually gutta-percha.

Aim: This study aimed to compare the push-out bond strength of Endosequence $\mathrm{BC}$ sealer with bioceramic coated and non-bioceramic coated gutta-percha.

Materials and methods: A total of 36 extracted human maxillary central incisors were decoronated to standardize the root length of $15 \mathrm{~mm}$. Working length was determined and Biomechanical preparation for all the samples was done with a Mtwo (VDW Company) rotary file till 40/.06. Samples were randomly divided into three groups containing 12 teeth in each group based on the obturation procedure, namely Group 1: Endosequence BC sealer along with Endosequence bioceramic coated gutta-percha $(n=12)$, Group 2: Endosequence $\mathrm{BC}$ sealer along with normal gutta-percha $(\mathrm{n}=12)$, Group 3: AH Plus sealer along with normal gutta-percha. All the samples were obturated using single cone technique. The specimens were sectioned orthogonally at middle third to obtain three sections of $1 \mathrm{~mm}$ thick. All the samples were subjected to the push-out bond strength test with the universal testing machine. The data were subjected to one-way Analysis of Variance (ANOVA) followed by post hoc analysis.

Results: Samples obturated with Endosequence BC sealer with Endosequence bioceramic coated gutta-percha showed the maximum push-out bond strength followed by Group 3 and Group 2. One-way Anova showed significant differences $(\mathrm{p}=0.021)$ among the groups. In posthoc analysis, the specimens from group 1 exhibited significant differences $(\mathrm{p}=0.016)$ with the group 2 specimens. Conclusion: The push-out bond strength of Endosequence Bioceramic sealer with Endosequence Bioceramic coated gutta-percha was significantly higher than that of Endosequence Bioceramic sealer with normal gutta-percha and $\mathrm{AH}$ Plus sealer with normal gutta-percha.

\section{Introduction}

The sound philosophy of endodontic therapy is to maintain a tooth in function in the dental arch following pulp pathology and sequelae, ideally in a way that is 
thorough and efficient. The success of endodontic therapy depends on thorough debridement of the root canal system, elimination of pathogenic organisms by establishing a fluid impervious seal. Gutta-percha is a commonly used obturating material. Gutta-percha does not bond to root dentin; hence, it is used in conjunction with a root canal sealer [1]. Traditionally, Zinc oxide Eugenol (ZoE) based materials are used as root canal sealers. However, they have some inherent drawbacks, including their inability to strengthen the root, as it does not adhere to dentin, microleakage, and the solubility of sealer. These shortcomings of ZoE sealants make their prognosis dilemmatic and unassured [2,3]. Hence, newer endodontic sealers are constantly being developed to provide enhanced properties.

$\mathrm{AH}$ Plus is an epoxy-resin based sealer, that is considered as the gold standard because of its physical properties [2]. The ability of this sealer to flow and its long-term polymerization time makes this sealer to penetrate deeper into the dentinal tubules and form strong mechanical interlocking between dentin and sealer.

Endosequence BC sealer is a recently introduced sealer, composed of zirconium oxide, calcium silicates, calcium phosphate monobasic, calcium hydroxide, and various filling and thickening agents. It is available in a premixed calibrated syringe with intracanal tips. As a hydrophilic sealer, it utilizes moisture within the canal to complete the setting reaction, and it does not shrink on setting [4]. Endosequence BC gutta-percha points are the latest innovative materials introduced into the field of dentistry [5]. Unlike the traditional GP points, these are subjected to a patented process of impregnating and coating each cone with bioceramic nanoparticles; they bond with the bioceramic particles in $\mathrm{BC}$ sealer to form a true gap-free seal. However, there is no adequate literature available on the bond strength of these sealant materials with the obturating materials. Therefore, this in vitro study was designed to compare the push-out bond strength of Endosequence BC sealer with bioceramic coated gutta-percha and non-bioceramic coated gutta-percha using the universal testing machine.

\section{Materials and methods}

A total of 36 specimens, which comprises 12 specimens in each group were used in this study, and it was confirmed using the G power software at a $95 \%$ confidence interval.

\subsection{Preparation and obturation of root canals}

A total of 36 extracted human maxillary central incisors were collected from the Department of Oral and Maxillofacial Surgery, Vishnu Dental College, Bhimavaram, Andhra Pradesh, India. The maxillary central incisors with a single root and single canal were included in the study. The teeth with calcified canals, cracks or fractures, development defects, multiple canals, root caries, and endodontically treated teeth were excluded. For standardization, all the samples were decoronated to a length of $15 \mathrm{~mm}$ by using a double-faced diamond disc (KG Sorensen, Barueri, SP, Brazil). Pulpal tissue extirpation was done, and the working length was determined. Biomechanical preparation for all the samples was done in crown-down motion using Mtwo rotary nickel-titanium files (VDW, Munich, Germany) till 40/.06 size. Canals were irrigated between the use of files with $5 \mathrm{ml}$ of $3 \%$ Sodium hypochlorite (Prime dental PVT LTD., India). All canals were irrigated with $3 \mathrm{ml}$ of $17 \%$ ethylene di amine tetra acetic acid (DESmear, Anabond Stedman pharma research, India) to remove the smear layer. Final rinse performed by using $5 \mathrm{~mL}$ of distilled water to remove any remaining irrigating solution. All the irrigation procedure was followed using a side vented needle placed $1 \mathrm{~mm}$ short of the apical foramen. The canals were dried with sterile absorbent paper points (Prime Dental PVT LTD., India.) after irrigation. All intracanal procedures were done by a single operator to eliminate inter-operator variability.

Teeth were then randomly divided into three experimental groups using computer-generated sequence allocation, consisting of 12 teeth each $(n=12)$ based on the obturation procedure.

In Group 1, EndoSequence BC sealer (Brasseler, Savannah, GA, USA) syringe was inserted into coronal one third and gently dispensed a small amount of sealer into the canal by compressing the plunger of the syringe. Then by using a 15 hand file canal walls are lightly coated with the existing sealer in the canal. All the samples were obturated using single cone obturation technique with ISO number 40/.06 Endosequence $\mathrm{BC}$ master cone GP coated with sealer.

The procedure was the same in Group 2 as that of Group 1, but normal 40/.06 master cone GP was used for obturation instead of bioceramic GP. 
In Group 3, AH Plus (Dentsply, Maillefer, Ballaigues, Switzerland) sealer is manipulated according to the manufacturer's instructions and is coated to canal walls using lentulospiral. Then all the samples were obturated using single cone obturation technique with ISO number 40/0.06 normal master cone GP. All the samples were coronally sealed using GIC type II (GC, Tokyo, Japan) and stored in distilled water for seven days to ensure complete setting of the sealers.

\subsection{Sample preparation for evaluation of bond strength}

Three $1 \mathrm{~mm}$ thick horizontal sections were prepared with the double-sided diamond disc under Continuous water-cooling from the middle third of each sample from all the groups.

\subsection{Evaluation of bond strength}

A suitable plunger, with $0.8 \mathrm{~mm}$ diameter, was selected such that the plunger did not contact surrounding dentinal walls when it was placed on the centre of the core material. The specimen was mounted on a universal testing machine (INSTRON-8801, Norwood, MA, USA). The load was applied at a crosshead speed of $0.5 \mathrm{~mm} / \mathrm{min}$ in an apico-coronal direction to avoid any interference caused by root canal taper. At the time of dislodgement, the strength was recorded in megapascals (MPa) for each specimen.

The obtained data were analyzed using the statistical package for the social sciences IBM SPSS Statistics version 22.0 software, USA, and One-way Analysis of Variance test followed by posthoc analysis were carried out.

\section{Results}

The mean push-out bond strength ( $\mathrm{MPa}$ ) and standard deviations (SD) of segments of all the three groups are given in table 1 . Group 1 samples showed the maximum push-out bond strength, and Group 2 samples exhibited the least bond strength.. One-way ANOVA test exhibited significant differences $(p=0.021)$ among the groups. Posthoc analysis showed significant differences $(p=0.016)$ between group 1 and group 2 specimens (Table 2) whereas group 3 specimens did not show significant differences with both the group 1 and group 2 specimens.

\section{Discussion}

Adherence of sealer to the root canal walls and GP are desirable properties for good, long term results $[6,7]$. Some of the physico-mechanical properties of sealers are specified in international standards such as EN-ISO 6876:2001, but they exclude certain properties such as adhesion to the canal wall [8]. Hence in the present study, the universal testing machine was used to compare the push-out bond strength of Endosequence $\mathrm{BC}$ sealer with bioceramic coated gutta-percha and non-bioceramic coated gutta-percha.

In the present study, Endosequence BC sealant material along with Endosequence bioceramic coated guttapercha (group 1) showed the maximum push-out bond strength compared to the other two groups. The reason for superior bond strength in group 1 specimens can be attributed to the bonding between Bioceramic particles found in BC sealer and the Bioceramic particles

Table 1: Mean push-out bond strength (MPa) and standard deviations of segments of all the 3 groups (One-way ANOVA).

\begin{tabular}{ccccc}
\hline Groups & Mean & Standard Deviation & Standard Error & Significance \\
\hline 1 & 3.8974 & 1.01620 & 0.16937 & \\
2 & 3.1456 & 1.19057 & 0.19843 & $0.021^{*}$ \\
3 & 3.4286 & 1.10314 & 0.18386 & \\
\hline
\end{tabular}

Table 2: Comparison of push-out bond strength (MPa) of segments (Posthoc analysis)

\begin{tabular}{ccccc} 
Groups & & Mean Difference & Standard Error & Significance \\
1 & 2 & 0.73389 & 0.26059 & $0.016^{*}$ \\
2 & 3 & 0.45083 & 0.26059 & 0.199 \\
& 3 & 0.28306 & 0.26059 & 0.525 \\
\hline
\end{tabular}

* Significant differences were observed among the groups. 
in BC points. This bonding forms a true gap-free seal single cohesive unit called the Monoblock, which is a primary Monoblock pattern [9]. This monoblock pattern improves the bond strength of the sealer with dentin.

The creation of primary Monoblock in the root canal system $[9,10]$ reduces the stresses that occur inside the tooth structure. Due to BC Sealer's ability to penetrate dentinal tubules and interact with dentine moisture, optimum dimensional stability and the least amount of shrinkage was obtained [11]. Hydroxyapatite is co-precipitated within the calcium silicate hydrate phase in setting reaction to produce a composite-like structure, reinforcing the set cement [12]. Similar to this present study, Kouvas $\mathrm{V}$ et al. (1998) [13] also concluded that the innovative Bioceramic-based sealer (Endosequence) might have the potentiality to strengthen endodontically treated teeth to a level comparable to that of intact teeth.

In the present study, Group 3 showed better results than Group 2. The higher bond strength obtained with Group 3 compared to Group 2. It can be attributed to its ability to combine with the amino groups that are exposed in collagen and form strong covalent bonds between the resin and collagen upon the opening of the epoxide ring $[10,14]$. The low bond strength value of Group 3 compared to Group 1 can be attributed to the fact that $\mathrm{NaOCl}$ despite its disinfectant properties, being a deproteinizing agent, it can degenerate dentin by collagen dissolution, affecting the resin sealer penetration and hindering the formation of a consistent hybrid layer. Furthermore, NaOCl breaks down into sodium chloride and oxygen that interfere with resin sealer (AH Plus) polymerization, causing strong inhibition at the sealer-dentin interface and hence decreasing the bond strength [15]. The results are in accordance with a study in which the bond strength of two sealants was compared with respect to the presence or absence of the smear layer. The adhesion strength of the BC-Sealer was superior to that of the AH-Plus without smear layer [16].

Group 2 showed the least bond strength values compared to other groups. In group 3, even though $\mathrm{NaOCl}$ decreased the push-out bond strength values of $\mathrm{AH}$ Plus sealer, it had more bond strength value than the Group 2. The reason for this lower Push-out bond strength in group 2 can be attributed to the poor bonding efficacy of the Endosequence BC sealer with the normal gutta-percha cones [17]. The results are in accordance with various studies $[18,19]$ in which $\mathrm{AH}$ Plus showed greater bond strength as it is less soluble and epoxy resin component of $\mathrm{AH}$ Plus after water sorption may also have increased its resistance against dislodgement.

\section{Conclusion}

From this study, it can be concluded that the push-out bond strength of Endosequence Bioceramic sealer with Endosequence Bioceramic coated gutta-percha was significantly higher than that of Endosequence Bioceramic sealer with normal gutta-percha and $\mathrm{AH}$ Plus sealer with normal gutta-percha.

However, further in-vitro and in-vivo studies with a larger sample and the teeth with more complex anatomies are required to validate its clinical efficacy and applications.

Conflicts of interest: Authors declared no conflicts of interest.

\section{Financial support: None}

\section{References}

1. Lacey S, Pitt Ford TR, Watson TF, Sherriff M. A study of the rheological properties of endodontic sealers. Int Endod J 2005; 38:499-504. https:// doi.org/10.1111/j.1365-2591.2005.00953.X

2. Tyagi S, Mishra P, Tyagi P. Evolution of root canal sealers: An insight story. Eur J Gen Dent 2013; 2:199 -218. https://doi.org/10.4103/2278-9626.115976

3. Kadali N, Alla RK, Vineeth G, Ramaraju AV, Suresh Sajjan MC, Raju RV. Mineral Trioxide Aggregate: An overview of composition, properties and clinical applications. Int J Dent Mater 2020;2(1): 11-18. https://doi.org/10.37983/IJDM.2020.2103

4. Sagsen B, Ustu Y, Demirbuga S, Pala K. Push-out bond strength of two new calcium silicate-based endodontic sealers to root canal dentine. Int Endod $\mathrm{J}$ 2011; 44:1088-91. https://doi.org/10.1111/j.1365$\underline{\text { 2591.2011.01925.X }}$

5. Al-Haddad AY, Kutty MG, Che Ab Aziz ZA. Pushout bond strength of experimental apatite calcium phosphate based coated gutta-percha. International Journal of Biomaterials. 2018 Aug 1;2018. https:// doi.org/10.1155/2018/1731857 
6. Shivanna V. The effect of different irrigating solutions on the push out bond strength of endodontic sealer to dentin and assessing the fracture modes: An In-vitro study. J Int Clin Dent Res Organ. 2014;6 (2):86. https://doi.org/10.4103/2231-0754.143483

7. Hegde V, Arora S. Sealing ability of three hydrophilic single cone obturation systems: An in vitro glucose leakage study. Contemp Clin Dent. 2015;6 (Suppl 1): S86. https://doi.org/10.4103/0976$\underline{237 X .152953}$

8. Razmi H, Bolhari B, Dashti NK, Fazlyab M. The effect of canal dryness on bond strength of bioceramic and epoxy-resin sealers after irrigation with sodium hypochlorite or chlorhexidine. Iran Endod J. 2016;11(2):129.

9. Sharma $\mathrm{S}$. The viability of current obturating systems as Replacement Endodontic Monoblocks - A 3Dimensional Finite Element Analysis. Endodontology. 2014 Dec;26(2).

10. Sly MM, Moore BK, Platt JA, Brown CE. Push-out bond strength of a new endodontic obturation system (Resilon/Epiphany). J Endod. 2007;33(2):160-2. https://doi.org/10.1016/j.joen.2006.09.014

11. Bayram H, Brayam E, Kanber M, Celikten B, Saklar F. Effect of different chelating solutions on the pushout bond strength of various root canal sealers. Biomed Res 2017; (Special issue): S401-6.

12. Gesi A, Raffaelli O, Goracci C, Pashley DH, Tay FR, Ferrari M. Interfacial strength of Resilon and guttapercha to intraradicular dentin. J Endod. 2005;31 (11):809-13.

https://doi.org/10.1097/01.don.0000158230.15853.b7

13. Kouvas V, Liolios E, Vassiliadis I, ParissisMessimeris S, Boutsioukis A. Influence of smear layer on depth of penetration of three endodontic sealers: an SEM study. Dent Traumatol. 1998;14 (4):191-5. $\quad$ https://doi.org/10.1111/j.16009657.1998.tb00836.x

14. Ungor M, Onay EO, Orucoglu H. Push-out bond strengths: the Epiphany-Resilon endodontic obturation system compared with different pairings of Epiphany, Resilon, AH Plus and gutta-percha. Int Endod J. 2006;39(8):643-7. https://doi.org/10.1111/j.1365-2591.2006.01132.x

15. Bojar WI, Czarnecka BE, Prylinski M, Walory JA. Shear bond strength of epoxy resin-based endodontic sealers to bovine dentin after ozone application. Acta Bioeng Biomech. 2009;11(3):41-5.

16. Shokouhinejad N, Gorjestani H, Nasseh AA, Hoseini A, Mohammadi M, Shamshiri AR. Push-out bond strength of gutta-percha with a new bioceramic sealer Comparison of push-out bond strength of bio ceramic sealer with bio ceramic coated gutta-percha and nonbio ceramic coated gutta-percha in the presence or absence of smear layer. Aust Endod J. 2013; 39 (3):102-6.

https://doi.org/10.1111/j.1747-4477.2011.00310.x

17. Gade VJ, Belsare LD, Patil S, Bhede R, Gade JR. Evaluation of push-out bond strength of endosequence $\mathrm{BC}$ sealer with lateral condensation and thermoplasticized technique: An in vitro study. J Conserv Dent 2015; 18:124-7.

https://doi.org/10.4103/0972-0707.153075

18. Lee KW, Williams MC, Camps JJ, Pashley DH. Adhesion of endodontic sealers to dentin and guttapercha. Journal of endodontics. 2002;28(10):684-8. https://doi.org/10.1097/00004770-200210000-00002

19. Nagas E, Uyanik MO, Eymirli A, Cehreli ZC, Vallittu PK, Lassila LV, Durmaz V. Dentin moisture conditions affect the adhesion of root canal sealers. Journal of endodontics. 2012;38(2):240-4. https://doi.org/10.1016/j.joen.2011.09.027 